\title{
Novo gênero de Acanthoderini (Coleoptera, Cerambycidae)
}

\author{
Carlos Eduardo de Alvarenga Julio ${ }^{1,2}$ \& Miguel A. Monné ${ }^{1,3}$
}

${ }^{1}$ Departamento de Entomologia, Museu Nacional, Universidade Federal do Rio Janeiro, Quinta da Boa Vista, São Cristóvão, 20940-040,
Rio de Janeiro-RJ, Brasil.
${ }^{2}$ Bolsista de Pós-Doutorado CNPq (Proc. 150583/2003-6).
${ }^{3}$ Pesquisador do CNPq.

\begin{abstract}
New genus of Acanthoderini (Coleoptera, Cerambycidae). Trichoanoreina new genus, type species $T$. albomaculata, new species, are described from Espirito Santo and São Paulo, Brazil. The new genus is compared with Anoreina Bates, 1861
\end{abstract}

KEYWORDS. Acanthoderini; Cerambycidae; Lamiinae; Neotropical; taxonomy.

RESUMO. Novo gênero de Acanthoderini (Coleoptera, Cerambycidae). Um novo gênero de Acanthoderini, Trichoanoreina gen. nov., e nova espécie, T. albomaculata sp. nov., são descritos do Espírito Santo e São Paulo, Brasil. O novo gênero é comparado com Anoreina Bates, 1861.

PALAVRAS-CHAVE. Acanthoderini; Cerambycidae;Lamiinae; Neotropical; taxonomia.

O estudo de representantes da tribo Acanthoderini, depositados na coleção do Museu Nacional/Universidade Federal do Rio de Janeiro (MNRJ), permitiu a descrição de um novo gênero e espécie, baseada em espécimens coletados no Espírito Santo (Linhares) e São Paulo (São Paulo: Cantareira e Jabaquara).

\section{Trichoanoreina gen. nov.}

Espécie-tipo: Trichoanoreina albomaculata sp. nov.

Descrição. Superfície corporal totalmente revestida por pubescência decumbente. Cerdas longas e eretas recobrem as genas, o lado interno das antenas, os élitros e as pernas. Cabeça um pouco convexa, com sutura coronal desde o occiput até a margem inferior da fronte. Lobos oculares inferiores com, aproximadamente, 1,5 vezes o comprimento das genas nos machos e com o mesmo comprimento nas fêmeas; lobos oculares superiores tão distantes entre si quanto, aproximadamente, duas vezes a largura de um lobo nos machos e quatro vezes nas fêmeas. Antenas, com onze artículos, ultrapassam os ápices elitrais nos machos e apenas os atingem nas fêmeas; escapo subcilíndrico; demais antenômeros cilíndricos, o III o mais longo e o XI afilado no ápice.

Protórax mais largo que longo; junto às margens anterior e posterior uma fileira de pontos grossos e profundos; lados com proeminência discreta. Pronoto com a região central aplanada. Escutelo triangular. Processo prosternal regularmente curvo, com a largura subigual à das cavidades procoxais; processo mesosternal plano, com o dobro da largura das cavidades mesocoxais; metasterno com uma elevação anterior em forma de $\mathrm{U}$, sendo o centro do U deprimido. Élitros planos com ligeiro declive posterior; margens externas subparalelas; disco com pontuação densa, grossa e profunda; região centro-basal com elevação discreta; úmeros ligeiramente proeminentes; ápices sub-retos. Pernas dos machos mais robustas; fêmures clavados; profêmures não pedunculados; mesofêmures com pedúnculo curto e curvo na base da clava; metafêmures com pedúnculo reto e alongado. Tarsômero V tão longo quanto os demais reunidos. Urosternito $\mathrm{V}$ das fêmeas com o mesmo comprimento dos dois anteriores reunidos.

Discussão. Assemelha-se a Anoreina erigido por Bates (1861:149) pelo aspecto do protórax, que tem lados com proeminência discreta e pronoto plano na região central; pelos élitros sub-planos com ligeira elevação centro-basal e margens externas sub-paralelas e pelo aspecto das pernas, com os fêmures clavados, os profêmures não pedunculados, os mesofêmures com pedúnculo curto e curvo na base da clava e os metafêmures com pedúnculo reto e alongado. Distingue-se de Anoreina, principalmente, pelas longas cerdas eretas que recobrem grande parte da superfície corporal; pelas antenas mais curtas nos machos que ultrapassam os ápices elitrais por quatro antenômeros; pela presença de uma fileira de pontos grossos e profundos junto às margens anterior e posterior do protórax; pela superfície elitral recoberta por uma pontuação densa, grossa e profunda e pelo aspecto do metasterno, com elevação anterior em forma de $\mathrm{U}$, sendo o centro do $\mathrm{U}$ deprimido. Em Anoreina: cerdas longas e eretas presentes, apenas, no lado interno dos antenômeros basais; antenas, dos machos, ultrapassam os ápices elitrais por, no mínimo, cinco antenômeros; pontuação, quando presente, fina e esparsa junto às margens anterior e posterior do protórax; pontuação do disco elitral fina e esparsa e, se grossa e profunda, restrita à metade basal; metasterno plano anteriormente, sem elevação em forma de $\mathrm{U}$.

Etimologia. Grego, trichos = cabelo, pêlo. Alusivo à presença de cerdas longas na superfície corporal. 


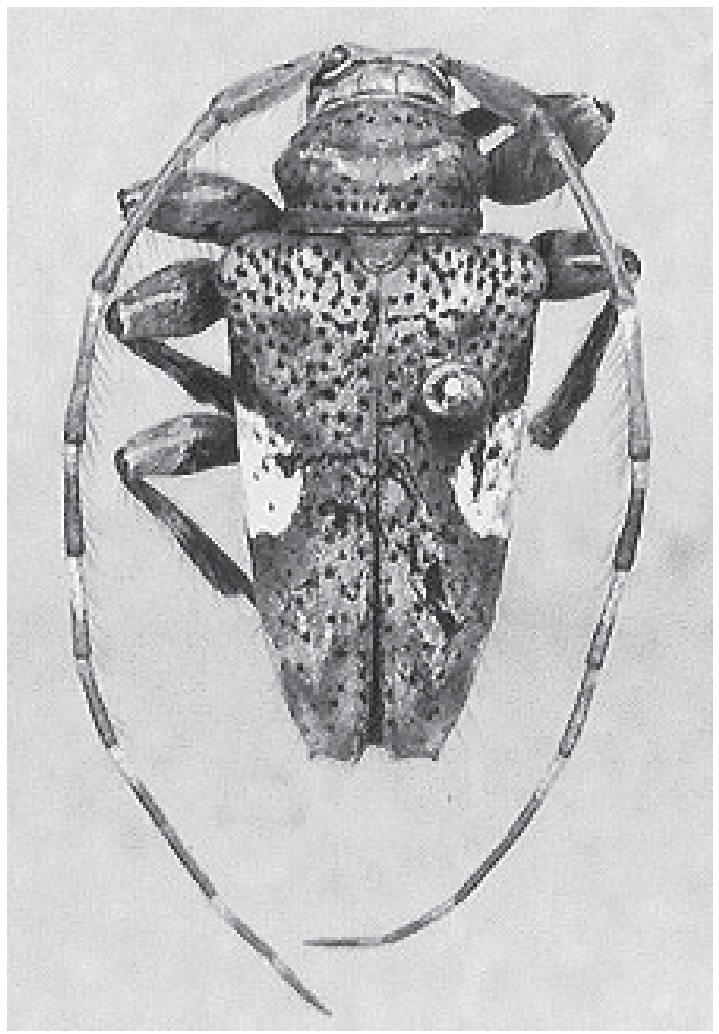

Fig. 1. Trichoanoreina albomaculata sp. nov., holótipo macho (MNRJ), Linhares (Parque Sooretama), Espírito Santo, Brasil, comprimento 6,1 mm.

\section{Trichoanoreina albomaculata sp. nov.}

Descrição. Macho. Tegumento castanho-avermelhado. Superfície corporal recoberta, na sua maior parte, por pubescência decumbente castanho-clara. Base dos antenômeros III-XI, metasterno e abdômen revestidos por pubescência esbranquiçada. Região mediana dos élitros com mancha semi-circular de pubescência decumbente esbranquiçada, a base do semi-círculo toca a margem lateral do élitro e o ápice não atinge a margem sutural, alcançando o meio do élitro. Cerdas longas e eretas castanho-escuras recobrem abundantemente as genas, o lado interno das antenas, os élitros e as pernas. Cabeça sem pontos, ligeiramente convexa; fronte sub-reta; lobos oculares unidos por uma fileira de, aproximadamente, três omatídios. Antenas ultrapassam os ápices elitrais por quatro antenômeros; escapo com o mesmo comprimento do antenômero IV e com, aproximadamente, $2 / 3$ do comprimento do III; antenômeros V-XI com, aproximadamente, o mesmo comprimento, um pouco mais curtos que o IV.

Élitros com pontuação mais densa na metade basal e pontos granulados no 1/4 basal; Ápices ligeiramente sinuosos, com pequeno prolongamento externo espiniforme.

Fêmea. Lobos oculares unidos por uma fileira de dois omatídios. Antenas apenas atingem os ápices elitrais. Urosternito $\mathrm{V}$ com um pequeno sulco longitudinal no centro do $1 / 3$ anterior.

Dimensões, em mm, respectivamente macho e fêmea. Comprimento total, 6,1-8,4 e 7,0-8,2; comprimento do protórax, 1,1-1,6 e 1,2-1,5; maior largura do protórax, 2,1-2,7 e 2,2-2,6; comprimento elitral, 4,4-6,4 e 5,2-6,0; largura umeral, 2,6-3,9 e $3,1-3,5$.

Material-tipo. Holótipo macho, BRASIL. Espírito Santo: Linhares (Parque Sooretama), X.1963, F. M. Oliveira. Parátipos: macho, mesma localidade do holótipo, XI.1964, F. M. Oliveira, Werner e C.A.Seabra col. São Paulo: Cantareira, macho, XI.1941; Jabaquara, fêmea, XII.1937 e fêmea, XI.1943, todos H. Zellibor col. Todos no MNRJ.

Comentários. A coloração da pubescência decumbente que reveste a superfície corporal pode variar do castanho ao esbranquiçado e a mancha elitral mediana pode apresentar um formato mais arredondado.

Etimologia. Latim, albus $=$ branco e macula $=$ mancha, marca, sinal. Alusivo à mancha esbranquiçada na região mediana dos élitros.

\section{REFERÊNCIAS}

Bates, H. W. 1861. Contributions to an insect fauna of the Amazon Valley. Coleoptera: Longicornes. The Annals and Magazine of Natural History, London, 8: 147-152. 